\title{
Involuntary Unemployment and Fiscal Policy for Full-Employment
}

\author{
Yasuhito Tanaka \\ Faculty of Economics, Doshisha University, Kyoto, Japan \\ Email: yatanaka@mail.doshisha.ac.jp
}

How to cite this paper: Tanaka, Y. (2020). Involuntary Unemployment and Fiscal Policy for Full-Employment. Theoretical Economics Letters, 10, 745-757. https://doi.org/10.4236/tel.2020.104046

Received: June 21, 2020

Accepted: July 31, 2020

Published: August 3, 2020

Copyright ( 2020 by author(s) and Scientific Research Publishing Inc. This work is licensed under the Creative Commons Attribution International License (CC BY 4.0).

http://creativecommons.org/licenses/by/4.0/

\begin{abstract}
In this paper we show the existence of involuntary unemployment based on consumers' utility maximization and firms' profit maximization behavior under perfect competition with decreasing or constant returns to scale technology using a three-period overlapping generations (OLG) model with a childhood period as well as younger and older periods, and analyze the effects of fiscal policy financed by tax and budget deficit (or seigniorage) to realize full-employment under a situation with involuntary unemployment. We show the following results. 1) In order to maintain the steady state where employment increases at some positive rate, we need a budget deficit (Proposition 1). 2) If the full-employment state is realized, we do not need budget deficit to maintain full-employment (Proposition 2).
\end{abstract}

\section{Keywords}

Involuntary Unemployment, Three-Period Overlapping Generations Model, Perfect Competition

\section{Introduction}

In this paper we analyze the effects of fiscal policy to realize full-employment under a situation with involuntary unemployment. Involuntary unemployment occurs when an individual is willing to work at the prevailing wage yet is unemployed. Otaki (2009) says that there exists involuntary unemployment for two reasons: i) the nominal wage rate is set above the reservation nominal wage rate; and ii) the employment level and economic welfare never improve by lowering the nominal wage rate. Umada (1997) derived an upward-sloping labor demand curve from the mark-up principle for firms, and argued that such an upward-sloping labor demand curve leads to the existence of involuntary unem- 
ployment without wage rigidity ${ }^{1}$. But his model of firm behavior is ad-hoc. We consider consumers' utility maximization and firms' marginal cost pricing behavior in an overlapping generations (OLG) model under perfect competition according to Otaki (2011) and Otaki (2015), and demonstrate the existence of involuntary unemployment without the assumption of wage rigidity. Also, we analyze the effects of fiscal policy financed by tax and budget deficit (or seigniorage). We show the following results.

1) In order to maintain the steady state where employment increases at some positive rate, we need a budget deficit. (Proposition 1)

2) If the full-employment state is realized, we do not need budget deficit to maintain full-employment. (Proposition 2)

From these results we can say that in order to realize full-employment from a state with involuntary unemployment we need budget deficit of the government. However, when full-employment is realized, in order to maintain full-employment we need balanced budget. Therefore, additional government expenditure to realize fill-employment should be financed by seigniorage not public debt.

We assume indivisibility of the labor supply. As discussed by Otaki (2015) (Theorem 2.3) and Otaki (2012), if the labor supply is divisible and very small, no unemployment exists. About the indivisible labor supply Hansen (1985) is an important work. He studies the existence of unemployed workers and fluctuations in the rate of unemployment over the business cycle with indivisible labor supply. To treat an indivisible labor supply in a representative agent model he assumes that people choose lotteries rather than hours worked. Each person chooses a probability of working, then a lottery determines whether or not he actually works. There is a contract between firms and individuals that commits the individual to work the predetermined number of hours with the probability which is chosen by an individual. The contract is being traded, so the individual is paid whether he works or not. The firm provides complete unemployment insurance to the workers. In this paper we do not consider a representative worker from the entire workforce, including the employed and unemployed. We consider utility maximization by distinguishing between the employed and the unemployed individuals. Unemployed individuals are not insured.

In the next section we analyze the relationship between the indivisibility of the labor supply and the existence of involuntary unemployment under perfect competition with decreasing or constant returns to scale technology using a three-period OLG model with a childhood period as well as younger (working) and older (retired) periods. Also, we consider pay-as-you-go pension system for the older generation. In Section 3 we examine the effects of a decrease in the nominal wage rate. In our three-period OLG model with pay-as-you-go pension, an increase in the employment due to reductions in the nominal wage rate and the price of the good (by the so-called real balance effect) might be small or even negative. In Section 4 we study the fiscal policy financed by tax and budget defi-

${ }^{1}$ Lavoie (2001) presented a similar analysis. 
cit (or seigniorage).

The main innovation and contribution of this paper are as follows.

1) Traditional analysis treated all workers as if they were in the same situation. However, we analyze utility maximization of employed consumers and that of unemployed consumers separately.

2) We show the existence of involuntary unemployment without assuming rigidity of nominal or real wage rate, and based on the results we examine the features of fiscal policy to realize full-employment.

As we will state in the concluding remarks, the main limitation of this paper is that the good is produced by only labor and there exists no capital and investment of firms. A study of the problem of involuntary unemployment and fiscal policy in such a situation is the theme of future research.

\section{Indivisible Labor Supply and Involuntary Unemployment}

\subsection{Consumers}

We consider a three-period (0: childhood, 1: younger or working, and 2: older or retired) OLG model under perfect competition. It is a re-arrangement and an extension of the model put forth by Otaki (2007), Otaki (2009), and Otaki (2015). The structure of our model is as follows.

1) There is one factor of production, labor, and there is one good which is produced under perfect competition with decreasing or constant returns to scale technology.

2) Consumers consume the good during the childhood period (Period 0). This consumption is covered by borrowing money from the younger generation and the government scholarship. They must repay these debts in their Period 1. However, unemployed consumers cannot repay their own debts. Therefore, we assume that unemployed consumers receive unemployment benefits from the government, which are covered by taxes on employed consumers of the younger generation.

3) During Period 1, consumers supply one unit of labor, repay the debts and save money for their consumption in Period 2. They also pay taxes for the pay-as-you-go pension system for the older generation.

4) During Period 2, consumers consume the good using their savings carried over from their Period 1 earnings, and receive the pay-as-you-go pension, which is a lump-sum payment. They are covered by taxes on employed consumers of the younger generation.

5) Consumers determine their consumption in Periods 1 and 2 and the labor supply at the beginning of Period 1. We assume that their consumption during the childhood period is constant.

We use the following notation.

$c_{i}:$ consumption of an individual in Period $i, i=1,2$. 
$D$. consumption of an individual in Period 0, which is constant.

$p_{i}$ : the price of the good in Period $i, i=1,2$.

$\rho=\frac{p_{2}}{p_{1}}:$ (expected) inflation rate (plus one).

$W$ : nominal wage rate.

$R$ : unemployment benefit for an unemployed individual. $R=D$.

$\hat{D}$ : consumption in the childhood period of a next generation consumer.

$Q$ : pay-as-you-go pension for an individual of the older generation.

$\Theta$ : tax payment by an employed individual for the unemployment benefit.

$\hat{Q}$ : pay-as-you-go pension for consumers of the younger generation when they retire.

$\Psi$ : tax payment by an employed individual for the pay-as-you-go pension.

$\Pi$ : profits of firms which are equally distributed to each consumer.

$L$ : total employment.

$L_{f}$ : population of labor or employment during the full-employment state.

$y(L)$ : labor productivity, which is deceasing or constant with respect to the employment, $y^{\prime} \leq 0$.

$\delta$ is the definition function. If a consumer is employed, $\delta=1$; if he is unemployed, $\delta=0$. We define the employment elasticity of the labor productivity as follows,

$$
\zeta=\frac{y^{\prime}}{\frac{y(L)}{L}} .
$$

We assume that $-1<\zeta \leq 0$, and $\zeta$ is constant. Decreasing (constant) returns to scale means that $\zeta<0 \quad(\zeta=0)$.

Since the taxes for unemployed consumers' debts are paid by employed consumers, $D$ and $\Theta$ satisfy the following relationship.

$$
D\left(L_{f}-L\right)=L \Theta \text {. }
$$

This means

$$
L(D+\Theta)=L_{f} D .
$$

Also, since the taxes for the pay-as-you-go pension system are paid by employed consumers, $Q$ and $\Psi$ satisfy the following relationship.

$$
L_{f} Q=L \Psi .
$$

The utility of consumers of one generation over the three periods is

$$
U\left(c_{1}, c_{2}, D, \delta, \beta\right)=\alpha \ln c_{1}+(1-\alpha) \ln c_{2}+\gamma \ln D-\delta \ln \beta, 0<\alpha<1,0<\gamma<1 \text {. }
$$


$\ln \beta$ is disutility of labor. The budget constraint is

$$
p_{1} c_{1}+p_{2} c_{2}=\delta W+\Pi-D-\delta \Theta+\hat{Q}-\delta \Psi+(1-\delta) R .
$$

$p_{2}$ is the expected price of the good in Period 2. Since $R=D$,

$$
p_{1} c_{1}+p_{2} c_{2}=\delta W+\Pi-\delta D-\delta \Theta+\hat{Q}-\delta \Psi .
$$

The Lagrange function is

$$
\begin{aligned}
\mathcal{L}= & \alpha \ln c_{1}+(1-\alpha) \ln c_{2}+\gamma \ln D-\delta \ln \beta \\
& -\lambda\left[p_{1} c_{1}+p_{2} c_{2}-(\delta W+\Pi-\delta D-\delta \Theta+\hat{Q}-\delta \Psi)\right] .
\end{aligned}
$$

$\lambda$ is the Lagrange multiplier. Note that $D$ is constant. The first order conditions are

$$
\frac{\alpha}{c_{1}}=\lambda p_{1}, \frac{1-\alpha}{c_{2}}=\lambda p_{2} .
$$

From them we get

$$
\alpha=\lambda p_{1} c_{1}, 1-\alpha=\lambda p_{2} c_{2} .
$$

Thus,

$$
\lambda\left(p_{1} c_{1}+p_{2} c_{2}\right)=\lambda(\delta W+\Pi-\delta D-\delta \Theta+\hat{Q}-\delta \Psi)=1,
$$

and

$$
\begin{aligned}
& p_{1} c_{1}=\alpha(\delta W+\Pi-\delta D-\delta \Theta+\hat{Q}-\delta \Psi), \\
& p_{2} c_{2}=(1-\alpha)(\delta W+\Pi-\delta D-\delta \Theta+\hat{Q}-\delta \Psi) .
\end{aligned}
$$

Consumers' indirect utility is written as follows:

$$
\begin{aligned}
V= & \ln \alpha^{\alpha}(1-\alpha)^{1-\alpha}-\ln p_{1}^{\alpha} p_{2}^{1-\alpha}+\gamma \ln D \\
& +\ln (\delta W+\Pi-\delta D-\delta \Theta+\hat{Q}-\delta \Psi)-\delta \ln \beta,
\end{aligned}
$$

with

$$
\lambda=\frac{1}{\delta W+\Pi-\delta D-\delta \Theta+\hat{Q}-\delta \Psi} .
$$

The reservation nominal wage rate $W^{r}$ is a solution of the following equation.

$$
\ln \left(W^{r}+\Pi-D-\Theta+\hat{Q}-\Psi\right)-\ln \beta=\ln (\Pi+\hat{Q}) .
$$

This yields

$$
W^{r}=(\beta-1)(\Pi+\hat{Q})+(D+\Theta+\Psi) .
$$

The labor supply is indivisible. If $W>W^{r}$, the total labor supply is $L_{f}$. If $W<W^{r}$, it is zero. If $W=W^{r}$, consumers are indifferent to employment and unemployment, and no involuntary unemployment exists, even if $L<L_{f}$. The indivisibility of the labor supply might be because minimum standards of civi- 
lized life exists, even in an advanced economy (see Otaki (2015)) $)^{2}$.

The reservation real wage rate is

$$
\omega^{r}=\frac{W^{r}}{p_{1}}=(\beta-1)\left(\frac{\Pi}{p_{1}}+\frac{\hat{Q}}{p_{1}}\right)+\left(\frac{D}{p_{1}}+\frac{\Theta}{p_{1}}+\frac{\Psi}{p_{1}}\right) .
$$

If the real values of the profit, pay-as-you-go pension, consumption in the childhood period, tax payment for unemployment benefit and tax payment for pay-as-you-go pension are constant, $\omega^{r}$ is constant.

Otaki $(2007,2009,2015)$ assumes that the (nominal or real) wage rate is equal to the reservation (nominal or real) wage rate at the equilibrium. However, there exists no mechanism to equalize them. We do not assume that the wage rate is equal to the reservation wage rate. This is the most significant difference between this study and Otaki $(2007,2009,2015)$.

\subsection{Firms}

The total demand for the good by younger generation consumers is

$$
\begin{aligned}
c^{1} & =\frac{\alpha\left(W L+L_{f} \Pi-L D-L \Theta+L_{f} \hat{Q}-L \Psi\right)}{p_{1}} \\
& =\frac{\alpha\left(W L+L_{f} \Pi-L_{f} D+L_{f} \hat{Q}-L_{f} Q\right)}{p_{1}} .
\end{aligned}
$$

This is the sum of the demand of employed and unemployed consumers. Note that $\hat{Q}$ is the pay-as-you-go pension for younger generation consumers in their Period 2. Similarly, their total demand for the good in the second period is

$$
c^{2}=\frac{(1-\alpha)\left(W L+L_{f} \Pi-L_{f} D+L_{f} \hat{Q}-L_{f} Q\right)}{p_{2}} .
$$

Let $\bar{c}^{2}$ be the demand for the good by the older generation. Then

$$
\bar{c}^{2}=\frac{(1-\alpha)\left(\bar{W} \bar{L}+L_{f} \bar{\Pi}-L_{f} \bar{D}+L_{f} Q-L_{f} \bar{Q}\right)}{p_{1}},
$$

where $\bar{W}, \bar{\Pi}, \bar{L}, \bar{D}$ and $\bar{Q}$ are the nominal wage rate, the profits of firms, the employment, the debt of an individual, and the pay-as-you-go pension, respectively, during the previous period. Note that $Q$ is the pay-as-you-go pension for the older generation. Let

$$
M=(1-\alpha)\left(\bar{W} \bar{L}+L_{f} \bar{\Pi}-L_{f} \bar{D}+L_{f} Q-L_{f} \bar{Q}\right) .
$$

This is the total savings or the total consumption of the older generation consumers including the pay-as-you-go pensions they receive in their Period 2. It is the planned consumption that is determined in Period 1 of the older generation

${ }^{2} \mathrm{He}$ says "it is natural to assume that people do not reduce working hours when they are threatened by poverty. Such propensity to work is preserved even in advanced economies for people to maintain minimum standards of civilized life even though working adjoins non-negligible disutility. This lends legitimacy to the concept of the indivisibility of working hours per capita" (Sec. 2.3.2 in Otaki (2015)). 
consumers. Net savings is the difference between $M$ and the pay-as-you-go pensions in their Period 2, as follows:

$$
M-L_{f} Q .
$$

Their demand for the good is written as $\frac{M}{p_{1}}$. Government expenditure constitutes the national income as well as the consumption of the younger and older generations. Then, the total demand for the good is

$$
c=\frac{Y}{p_{1}} \text {. }
$$

$Y$ is the effective demand defined by

$$
Y=\alpha\left(W L+L_{f} \Pi-L_{f} D+L_{f} \hat{Q}-L_{f} Q\right)+G+L_{f} \hat{D}+M .
$$

Note that $\hat{D}$ is consumption in the childhood period of a next generation consumer. $G$ is the government expenditure, except for the pay-as-you-go pension, scholarships and unemployment benefits (see Otaki (2007), Otaki (2015) about this demand function). Now, we assume that $G$ is financed by seigniorage similarly to Otaki (2007) and Otaki (2009). In the later section, we will consider the government's budget constraint with respect to taxes.

Let $x$ and $z$ be the output and employment of a firm, respectively. We have $x=y(z) z$. Thus,

$$
\frac{\mathrm{d} z}{\mathrm{~d} x}=\frac{1}{y(z)+y^{\prime} z}=\frac{1}{(1+\zeta) y(z)} .
$$

The profit of the firm is

$$
\pi=p_{1} x-\frac{x}{y(z)} W .
$$

The condition for profit maximization under perfect competition is

$$
\begin{aligned}
p_{1}-\frac{y(z)-x y^{\prime} \frac{\mathrm{d} z}{\mathrm{~d} x}}{y(z)^{2}} W & =p_{1}-\frac{1-y^{\prime} z \frac{\mathrm{d} z}{\mathrm{~d} x}}{y(z)} W=p_{1}-\frac{1}{y(z)+y^{\prime} z} W \\
& =p_{1}-\frac{1}{(1+\zeta) y(z)} W=0 .
\end{aligned}
$$

Therefore,

$$
p_{1}=\frac{1}{(1+\zeta) y(z)} W
$$

This represents marginal cost pricing. Since at the equilibrium $x=c$ and $Z=L$, we obtain

$$
p_{1}=\frac{1}{(1+\zeta) y(L)} W
$$

With decreasing (constant) returns to scale, $-1<\zeta<0(\zeta=0)$. 


\subsection{Involuntary Unemployment}

The real wage rate is

$$
\omega=\frac{W}{p_{1}}=(1+\zeta) y(L) .
$$

Under decreasing (constant) returns to scale, since $\zeta$ is constant, $\omega$ is decreasing (constant) with respect to $L$. Aggregate supply of the good is equal to

$$
W L+L_{f} \Pi=p_{1} L y(L) .
$$

Aggregate demand is

$$
\begin{aligned}
& \alpha\left(W L+L_{f} \Pi-L_{f} D+L_{f} \hat{Q}-L_{f} Q\right)+G+L_{f} \hat{D}+M \\
& =\alpha\left[p_{1} L y(L)-L_{f} D+L_{f} \hat{Q}-L_{f} Q\right]+G+L_{f} \hat{D}+M .
\end{aligned}
$$

Since they are equal,

$$
p_{1} L y(L)=\alpha\left[p_{1} L y(L)-L_{f} D+L_{f} \hat{Q}-L_{f} Q\right]+G+L_{f} \hat{D}+M,
$$

or

$$
p_{1} L y(L)=\frac{\alpha\left(-L_{f} D+L_{f} \hat{Q}-L_{f} Q\right)+G+L_{f} \hat{D}+M}{1-\alpha} .
$$

In real terms ${ }^{3}$

$$
L y(L)=\frac{\alpha\left(-L_{f} D+L_{f} \hat{Q}-L_{f} Q\right)+G+L_{f} \hat{D}+M}{(1-\alpha) p_{1}},
$$

or

$$
L=\psi(L)=\frac{\alpha\left(-L_{f} D+L_{f} \hat{Q}-L_{f} Q\right)+G+L_{f} \hat{D}+M}{(1-\alpha) p_{1} y(L)}
$$

$L$ is obtained as a fixed point of $\psi(L)$. It cannot be larger than $L_{f}$. However, it may be strictly smaller than $L_{f}\left(L<L_{f}\right)$. Then, involuntary umemployment exists. Under decreasing returns to scale the real wage rate, $\omega=(1+\zeta) y(L)$, is decreasing with respect to $L$. If $\omega>\omega^{r}$ an increase in the employment reduces the difference between them. However, it cannot be guaranteed that they become equalized.

If we consider the following budget constraint for the government with a lump-sum tax $T$ on the younger generation consumers ${ }^{4}$,

$$
G=T \text {, }
$$

aggregate demand is

$$
\begin{aligned}
& \alpha\left(W L+L_{f} \Pi-G-L_{f} D+L_{f} \hat{Q}-L_{f} Q\right)+G+L_{f} \hat{D}+M \\
& =\alpha\left[p_{1} L y(L)-G-L_{f} D+L_{f} \hat{Q}-L_{f} Q\right]+G+L_{f} \hat{D}+M
\end{aligned}
$$

$3 \frac{1}{1-\alpha}$ is a multiplier.

${ }^{4}$ Of course, only employed consumers pay the taxes. $T$ denotes the total tax payment. 
Then, we obtain ${ }^{5}$

$$
L y(L)=\frac{\alpha\left(-L_{f} D+L_{f} \hat{Q}-L_{f} Q\right)+(1-\alpha) G+L_{f} \hat{D}+M}{(1-\alpha) p_{1}} .
$$

\subsection{Discussion Summary}

The real wage rate depends on the employment elasticity of the labor productivity and the employment level. But the employment level does not depend on the real wage rate. The real aggregate demand and the employment level are determined by the value of

$$
\frac{\alpha\left(-L_{f} D+L_{f} \hat{Q}-L_{f} Q\right)+G+L_{f} \hat{D}+M}{p_{1}} .
$$

If employment is smaller than the labor population, then involuntary unemployment exists.

When the real wage rate is larger than the reservation real wage rate, an increase in the employment reduces the difference between them under decreasing returns to scale technology. However, it cannot be guaranteed that they become equalized.

\subsection{The Case of Full-Employment}

If $L=L_{f}$, full-employment is realized. Then, (2) is re-written as

$$
L_{f} y\left(L_{f}\right)=\frac{\alpha\left(-L_{f} D+L_{f} \hat{Q}-L_{f} Q\right)+G+L_{f} \hat{D}+M}{(1-\alpha) p_{1}} .
$$

Since $L_{f}$ is constant, this is an identity not an equation. On the other hand, (2) is an equation not an identity. (4) should be re-written as

$$
\frac{\alpha\left(-L_{f} D+L_{f} \hat{Q}-L_{f} Q\right)+G+L_{f} \hat{D}+M}{(1-\alpha) p_{1}} \equiv L_{f} y\left(L_{f}\right) .
$$

This yields:

$$
p_{1}=\frac{1}{(1-\alpha) L_{f} y\left(L_{f}\right)}\left[\alpha\left(-L_{f} D+L_{f} \hat{Q}-L_{f} Q\right)+G+L_{f} \hat{D}+M\right] .
$$

Then, the nominal wage rate is determined by:

$$
W=(1+\zeta) y\left(L_{f}\right) p_{1} .
$$

\section{Effects of a Decrease in the Nominal Wage Rate}

In this paper's model, no mechanism determines the nominal wage rate except at the full-employment state. For example, when the nominal value of $G$ increases, the nominal aggregate demand and supply increase. If the nominal wage rate rises, the price also rises. If, when $G$ increases, the price rises considerably, 
then the output might not increase and involuntary unemployment might not decrease. If the price does not rise or rises only slightly, involuntary unemployment decreases. Now, we examine the effects on employment of a decrease in the nominal wage rate. A decrease in the nominal wage rate induces a decrease in the price of the good (see (1)), and it does not directly rescue involuntary unemployment. Proposition 2.1 in Otaki (2016) says

Suppose that the nominal wage sags. Then, as far as its indirect effects on the aggregate demand are negligible, this only results in causing a proportionate fall in the price level. In other words, a fall in the nominal wage never rescues workers who are involuntarily unemployed.

However, indirect effects on aggregate demand due to a fall in the nominal wage rate may exist. We assume that a reduction in the nominal wage rate and a reduction in the price are not predicted by consumers. If the price of the good falls, the real value of the older generation's savings increases. But, at the same time, a decrease in the price of the good increases the real value of the younger generation consumers' debts. These are the so-called real balance effects.

The real values of the following variables will be maintained even when both the nominal wage rate and the price fall.

$G / p_{1}:$ the government expenditure.

$\hat{D} / p_{1}$ : consumption in the childhood period of a next generation consumer.

$Q / p_{1}$ : pay-as-you-go pension for an older generation consumer.

$\hat{Q} / p_{1}$ : pay-as-you-go pension for a younger generation consumer when he retires.

On the other hand, the nominal value of $D$ and that of $M-L_{f} Q$, which is the older generation's net savings, does not change. Therefore, from (3), whether the fall in the nominal wage rate increases or decreases the effective demand depends on whether

$$
M-L_{f} Q-\alpha L_{f} D
$$

is positive or negative. If $D$ or $Q$ is large, (5) is negative, and the fall in the nominal wage rate increases involuntary unemployment.

\section{Steady State with an Increase in Employment by Fiscal Policy}

\subsection{Steady State with an Increase in Employment under Constant Price}

Consider a steady state where the employment $L$ increases at the rate $\eta-1>0$. If $\eta L<L_{f}$, involuntary unemployment exists even at the steady state. We assume $\rho=1$, that is, the constant price of the good. Consumers correctly predict that the price is constant. Let $T$ be the tax revenue which is not necessarily equal to $G$. Then, 


$$
p_{1} L y(L)=\alpha\left[p_{1} L y(L)-T-L_{f} D+L_{f} \hat{Q}-L_{f} Q\right]+G+L_{f} \hat{D}+M .
$$

At the steady sate, $\hat{D}=D$ and $\hat{Q}=Q$. Thus,

$$
p_{1} L y(L)=\alpha\left[p_{1} L y(L)-T-L_{f} D\right]+G+L_{f} D+M .
$$

The savings of the younger generation including the pay-as-you-go pension must be equal to $\eta M$. Therefore,

$$
(1-\alpha)\left[p_{1} L y(L)-T-L_{f} D\right]=G-T+M=\eta M .
$$

This means that:

$$
G-T=(\eta-1) M .
$$

From this we obtain the following proposition.

Proposition 1. In order to maintain the steady state where employment increases at some positive rate $(\eta-1>0)$, a budget deficit is required.

Let $G^{\prime}$ and $T^{\prime}$ be the government expenditure and tax revenue in the next period, (6) is written as

$$
p_{1} \eta L y(L)=\alpha\left[p_{1} \eta L y(L)-T^{\prime}-L_{f} D\right]+G^{\prime}+L_{f} D+\eta M .
$$

Suppose that the savings of the younger generation including the pay-as-you-go pension in the next period is equal to $\eta^{2} M$. Then,

$$
(1-\alpha)\left[p_{1} \eta L y(L)-T^{\prime}-L_{f} D\right]=G^{\prime}-T^{\prime}+\eta M=\eta^{2} M,
$$

and we obtain

$$
G^{\prime}-T^{\prime}=\eta(\eta-1) M
$$

This is the budget deficit which is necessary to realize an increase in employment in the next period.

On the other hand, if we suppose that the savings of the younger generation including the pay-as-you-go pension is equal to $\eta M$, we have

$$
(1-\alpha)\left[p_{1} \eta L y(L)-T^{\prime}-L_{f} D\right]=G^{\prime}-T^{\prime}+\eta M=\eta M .
$$

Then,

$$
G^{\prime}-T^{\prime}=0 .
$$

From this we obtain the following proposition.

Proposition 2. If $\eta L=L_{f}$, that is, the full-employment state is realized in the next period, we do not need budget deficit to maintain full-employment.

\subsection{Steady State with an Increase in Employment under Inflation or Deflation}

Next consider a steady state where the employment $L$ increases at the rate $\eta-1$, and the price of the good rises or falls at the rate $\rho-1$. If $\rho>1(<1)$, consumers correctly predict that the price rises (falls). Let $T$ be the tax revenue which is not necessarily equal to $G$. Then,

$$
p_{1} L y(L)=\alpha\left[p_{1} L y(L)-T-L_{f} D+L_{f} \hat{Q}-L_{f} Q\right]+G+L_{f} \hat{D}+M .
$$


At the steady sate, $\hat{D}=\rho D$ and $\hat{Q}=\rho Q$. Thus,

$$
p_{1} L y(L)=\alpha\left[p_{1} L y(L)-T-L_{f} D+(\rho-1) L_{f} Q\right]+G+\rho L_{f} D+M .
$$

The savings of the younger generation including the pay-as-you-go pension must be equal to $\rho \eta M$. Therefore,

$$
\begin{aligned}
& (1-\alpha)\left[p_{1} L y(L)-T-L_{f} D+(\rho-1) L_{f} Q\right] \\
& =G-T+(\rho-1)\left(L_{f} D+L_{f} Q\right)+M=\rho \eta M .
\end{aligned}
$$

This means that:

$$
G-T=(\rho \eta-1) M-(\rho-1)\left(L_{f} D+L_{f} Q\right) .
$$

We approximate $\rho \eta$ by $\rho+\eta-1$. Then,

$$
G-T=(\eta-1) M+(\rho-1)\left(M-L_{f} D-L_{f} Q\right)
$$

Without an increase in employment $(\eta=1)$, if $M>L_{f} D+L_{f} Q$, in order to maintain the steady state with a falling price $(\rho<1)$ (rising price $(\rho>1))$ a budget surplus (deficit) is required. If $M<L_{f} D+L_{f} Q$, we obtain the inverse results. Similarly to the previous case we need a budget deficit $(\eta-1) M$ to realize an increase in employment.

\subsection{Discussion}

From Propositions 1 and 2 we can say that in order to realize full-employment from a state with involuntary unemployment we need budget deficit of the government. However, when full-employment is realized, in order to maintain full-employment we need balanced budget. Therefore, additional government expenditure to realize fill-employment should be financed by seigniorage not public debt.

\section{Concluding Remark}

We have examined the existence of involuntary unemployment and the effects of fiscal policy using a three-generation OLG model under perfect competition with decreasing or constant returns to scale. We considered the case of an indivisible labor supply, and we assumed that the good is produced only by labor.

In future research, we want to analyze involuntary unemployment and fiscal policy in the following situations.

1) Divisible labor supply.

Even if labor supply is divisible, unless it is so small, involuntary unemployment may still exist.

2) Monopolistic competition with constant or increasing returns to scale technology.

3) Goods are produced by capital and labor, and there is investment of firms.

\section{Acknowledgements}

I appreciate the valuable comments and suggestions by the reviewers which sub- 
stantially improved the paper. This work was supported by the Japan Society for the Promotion of Science KAKENHI (Grant Number 18K01594).

\section{Conflicts of Interest}

The author declares no conflicts of interest regarding the publication of this paper.

\section{References}

Hansen, G. D. (1985). Indivisible Labor and Business Cycle. Journal of Monetary Economics, 16, 309-327. https://doi.org/10.1016/0304-3932(85)90039-X

Lavoie, M. (2001). Efficiency Wages in Kaleckian Models of Employment. Journal of Post Keynesian Economics, 23, 449-464. https://doi.org/10.1080/01603477.2001.11490293

Otaki, M. (2007). The Dynamically Extended Keynesian cross and the Welfare-Improving Fiscal Policy. Economics Letters, 96, 23-29. https://doi.org/10.1016/j.econlet.2006.12.005

Otaki, M. (2009). A Welfare Economics Foundation for the Full-Employment Policy. Economics Letters, 102, 1-3. https://doi.org/10.1016/j.econlet.2008.08.003

Otaki, M. (2011). A Pure Theory of Aggregate Price Determination. Theoretical Economics Letters, 1, 122-128. https://doi.org/10.4236/tel.2011.13026

Otaki, M. (2012). The Aggregation Problem in the Employment Theory: The Representative Individual Model or Individual Employees Model? Theoretical Economics Letters, 2, 530-533. https://doi.org/10.4236/tel.2012.25098

Otaki, M. (2015). Keynsian Economics and Price Theory: Re-Orientation of a Theory of Monetary Economy. Tokyo: Springer. https://doi.org/10.1007/978-4-431-55345-8

Otaki, M. (2016). Keynes's General Theory Reconsidered in the Context of the Japanese Economy. Tokyo: Springer. https://doi.org/10.1007/978-4-431-55915-3

Umada, T. (1997). Hi-jihatsuteki-shitsugyo no sonzai ni tsuite. [On the Existence of Involuntary Unemployment.] Yamaguchi Keizaigaku Zasshi, 45, 61-73. (In Japanese) 